\title{
La solidaridad en red: los trabajadores ferroviarios de Valparaíso entre los años 1973-1989
}

\section{Solidarity in a network: the railway workers of Valparaíso between 1973 and 1989}

\section{Erick Fuentes Góngora*}

*Red de Historia Oral y Archivos Orales - Chile

HTTPS://DOI.ORG/10.22370/PE.2019.8.2530

\section{Resumen:}

Durante el siglo XX el concepto de patrimonio se ha expandido y profundizado relevando especialmente lo monumental, pero en las últimas décadas su comprensión es cada vez más diversa al incorporar bienes, ideas, procesos y formas de vida que, hasta hace no mucho tiempo, simplemente no se consideraban o estaban desprovistas de cualquier tipo de valoración. Desde un punto de vista político, es interesante destacar la forma en cómo se ha abordado en Chile el patrimonio industrial y, en particular, el patrimonio ferroviario, todavía con un foco que privilegia las arquitecturas y tecnologías por sobre los procesos socioculturales de los hombres y mujeres que trabajaban allí. Estas notas de investigación ponen en valor la memoria del Complejo Ferroviario Barón de Valparaíso a partir de la constitución de un Archivo Oral basado en las voces que actualmente se encuentran en la memoria de sus portadores, visibilizando el patrimonio industrial ferroviario de la ciudad.

Palabras Clave: Patrimonio, gestión, industria, Ferrocarriles, trabajadores

\section{Abstract}

During the 20th century, the concept of heritage has expanded and deepened, especially relieving the monumental, but in recent decades its understanding has become increasingly diverse, incorporating goods, ideas, processes and ways of life that, until recently, were simply not considered or were not subject to any valuation. From a political point of view, it is interesting to highlight the way in which the industrial heritage, and in particular the railway heritage, has been addressed in Chile, still with a focus that privileges architectures and technologies over the socio-cultural processes of the men and women who worked there. These research notes highlight the memory of the Barón de Valparaíso Railway Complex from the constitution of an Oral Archive based on the voices that are currently in the memory of its bearers, making visible the railway industrial heritage of the city.

Keywords: Heritage, management, industry, Railways, workers

*erick.fuentes.gongora@gmail.com 


\section{INTRODUCCIÓN}



$\mathrm{n}$ los últimos años diversos investigadores han venido insistiendo sobre la necesidad de incorporar una perspectiva integral para los estudios patrimoniales, que incluya no sólo la tradicional dimensión arquitectónica-monumental sino, por sobre todo, la de los procesos socioculturales que dieron y/o dan sentido a dichos lugares. Con esa finalidad, entre los años 2009-2015 tuve la oportunidad de participar de un proyecto de investigación ${ }^{1}$ que pretendió poner en valor la memoria del Complejo Ferroviario Barón de Valparaíso a partir de la constitución de un Archivo Oral basado en las voces que actualmente se encuentran en la memoria de sus portadores, visibilizando el patrimonio industrial ferroviario de la ciudad.

Allí entonces la idea inicial fue la de analizar la conformación y desarrollo de la comunidad ferroviaria que -aún después de más de un siglo-, habita la zona aledaña al Complejo Ferroviario Barón con una serie de prácticas socioculturales que propenden al bienestar colectivo, tomando como base la narrativa oral de sus ex trabajadores, comprendiendo que ésta se constituye en una fuente primaria privilegiada para conocer una memoria de la ciudad de Valparaíso que en la actualidad se niega a desaparecer, interrogándose sobre su permanencia y continuidad. Y es que a pesar de haber sufrido una sistemática intervención política en el período comprendido entre los años 1973-1989² y, además de no contar a la fecha con una política pública para la gestión integral del patrimonio industrial local, este estudio pretendió poner en valor la memoria del trabajo y el paisaje industrial de la comunidad ferroviaria con el fin de dimensionar su impacto en el desarrollo urbano histórico de la ciudad "Patrimonio de la Humanidad", así como en la discusión sobre su presente y futuro.

LA INTERRUPCIÓN DE LA TRAYECTORIA HISTÓRICA DE LOS TRABAJADORES FERROVIARIOS

Fue en la Empresa de Ferrocarriles del Estado donde surgió un sindicalismo relevante en el país, mediante la organización de los 
y solidaridad de los mismos para lograr sus soluciones". De la misma manera se enuncia que la FEFCH "reconoce la necesidad de proyectar su acción conjunta y mancomunada con la Federación hermana Santiago Watt, Unión de Obreros, Asociación de Ferroviarios Jubilados, y como organismo rector a la Federación Industrial Ferroviaria de Chile" y que en el trabajadores en la Sociedad de Protección Mutua de Maquinistas y Fogoneros Santiago Watt (1893), que luego sería protagonista en la formación y adhesión de las principales organizaciones

nacionales de trabajadores, la Federación Obrera de Chile (FOCH, 1909-1936), organización que posteriormente fue llamada Confederación de Trabajadores de Chile (CTCH, 1936-1953) y que con la alianza con el Movimiento Unitario Nacional de Trabajadores (MUNT, de tendencia anarcosindicalista), dieron lugar a la actual Central Única de Trabajadores de Chile (CUT, 1953).

En el órgano oficial de la Federación de Empleados Ferroviarios de Chile (FEFCH) por el año 1972, la FIFCH publicó el texto "El gremio y su rol fundamental", dando cuenta del desarrollo social chileno de los últimos años se ha caracterizado sobre todo por las modificaciones y luego transformaciones cada vez más profundas al alero de la Unidad Popular. Según lo señala la lectura del documento, los trabajadores ferroviarios se encontraban trabajando para profundizar estas transformaciones, porque les parece estas les entregan una posibilidad cierta de responsabilizarse de las actividades de la vida social, económica, política y cultural chilena. Allí se indica que:

"En consonancia con los grandes cambios sociales de la hora presente, el XI CONGRESO NACIONAL DE LA FEDERACION INDUSTRIAL FERROVIARIA DE CHILE (sic), trazó un diagnóstico señera de esta realidad. El XI Congreso Nacional FIFCH, reafirmó por ello que 'el carácter principal que asume la acción sindical, en un Gobierno de los Trabajadores (sic), es la lucha por la defensa y por el fortalecimiento del proceso revolucionario chileno de cambios sociales. Puntualizando a la 
vez que la defensa y el fortalecimiento del Gobierno Popular (sic), es la única garantía para ver realmente asegurado nuestro bienestar material y espiritual, que el capitalismo nos había negado’. Por tal razón también este evento llamó a poner en práctica la más amplia acción unitaria del gremio. A fortalecer al máximo la Organización (sic), a robustecerla y unificarla, para que las tareas de conducción de la Empresa y sus frentes de producción, de un modo elocuente, muestren y expresen cómo la clase trabajadora, como también los ferroviarios, somos capaces de cumplir con nuestro rol histórico, dentro del proceso de estas grandes transformaciones sociales.

Y no caben dudas que el propio proceso social, en su dinámica, se constituye en un poderoso elemento aglutinador y fortalecedor de las posiciones organizativas de las masas laborales. Esto también se aquilata en la propia realidad actual de nuestro gremio ferroviario. Los últimos acontecimientos políticos y sociales que han remecido el país, no tomaron de sorpresa al gremio ferroviario, que se mostró ejemplarmente consciente de cuál debía ser su responsabilidad. Se respondió con incontrarrestable unidad de organización en los principales centros de actividad y a lo largo de toda la Red. Probó que estamos los ferroviarios en condiciones, tanto por las bases, como por sus organismos medios, intermedios y superiores, para acometer las más grandes tareas colectivas, en que se precisa del concurso cada vez mayor de los más amplios sectores ferroviarios. Aparte de ello, y cumplidas ya algunas metas preliminares para facilitar la incorporación de los trabajadores en la conducción de los ferrocarriles, en la Participación (sic) a través del Consejo de Administración, ahora habrá también de abrirse paso a las más rápida elección y constitución de los Comités de Producción Regionales y Zonales. De esto dependerá, junto a otras medidas de reestructuración organizativa gremial, el más completo éxito de la actividad ferroviaria de nuestro país, al servicio de toda la comunidad" (Revista FEFCH, 1972: 1).

En la misma revista del año 1972, la FEFCH publicó su declaración de principios, consignando que ésta "es una organización de 
lucha y cuyos objetivos principales son propender al bienestar económico y social de sus asociados y de defensa de los organismos estatales y particularmente de la Empresa de los Ferrocarriles del Estado" (p.2). Además, allí se señala que los trabajadores ferroviarios reconocen que "los problemas económicos y sociales de los trabajadores son comunes" y, por tanto, "es necesaria la unidad plano nacional, la FEFCH reconoce como organismo rector en la política económica y social de los trabajadores a la CUT, institución a la que le corresponde proyectar la acción conjunta de estos (p. 2).

Fernando Lizama, miembro del Consejo de Administración de la Empresa de los Ferrocarriles del Estado de Chile, desarrolla en la misma publicación una esclarecedora lectura del período que profundiza el proceso de participación de los trabajadores en la gestión de la Empresa en el texto "Participación: Un derecho y un deber" (Revista FEFCH: 14-15). Allí se da cuenta de la representación laboral que los trabajadores consiguieron mediante un convenio entre la CUT y el gobierno, donde se creó el Consejo de Administración de la Empresa, que "tiene una labor inmensa que cumplir en el futuro, llevando a efecto a corto plazo la constitución de los demás organismos de Participación a nivel de base [sic], interesando a nuestros compañeros en su creación y obligando a la organización gremial en su conjunto que es la responsable directa de ello" (Revista FEFCH: 14), indicando en su punto 30 que:

"La organización sindical o gremial de la Empresa tiene la responsabilidad de dirigir y orientar organizada, efectiva y creadoramente la participación de todos los trabajadores de la Empresa como condición fundamental para asegurar las transformaciones revolucionarias que nos abran el camino hacia la implantación del socialismo en Chile [sic]" (Revista FEFCH, 1972: 15)

La lectura del gremio ferroviario revestía entonces de amplia legitimidad a su articulación nacional y daba cuenta del protagónico rol que cumplía en la política sindical de la Unidad Popular:

"El cambio de la estructura del poder que estamos llevando a cabo, el progresivo papel directivo que en ella asumimos los 
trabajadores, la recuperación nacional de las riquezas básicas, la liberación de nuestra Patria de la subordinación a las potencias extranjeras, son la culminación de un largo proceso histórico. De esfuerzo por imponer las libertades políticas y sociales, de heroica lucha de varias generaciones de obreros, empleados y campesinos por organizarse como fuerza social, para conquistar el poder político y desplazar a los capitalistas del poder económico" (Revista FEFCH, 1972: 42).

Esta radicalización política de la organización ferroviaria y, del sector público en general, se contrasta con las acciones registradas en el mes de Octubre del mismo año por las fuerzas de la derecha nacionalista y paramilitar, siendo leídas por los trabajadores ferroviarios como "una asonada fascista" que busca crear las "condiciones encaminadas a la alteración del orden institucional", publicando dichas acciones en una cronología como testimonio del "espíritu democrático" de los enemigos del Gobierno Popular”. En la región de Valparaíso, la cronología terrorista consideraba algunos hitos como los siguientes:

“QUILPUE Oct. 16. - Dinamitados 30 metros de línea férrea. Descarrila la máquina y un carro del tren de pasajeros Quillota-Puerto. (...) VIÑA DEL MAR Oct. 21. - Bomba molotov a la línea férrea frente a Caleta Abarca. (...) VILLA ALEMANA Oct. 25. - Estalla bomba en paso bajo nivel de FF.CC. (...) SAN FELIPE Oct. 27. - Explosión destruye vía férrea, instantes después de pasar hacia Los Andes máquina 2407. (...) VIÑA DEL MAR Oct. 28. Manifestantes de 'Patria y Libertad' atacan tienda García que no acató paro, y vuelcan dos automóviles" (Revista FEFCH, 1972: 29-30).

EL DESMANTELAMIENTO DE LA UTOPÍA Y LA INSTALACIÓN DEL ORDEN NEOLIBERAL

Estos acontecimientos son algunos de los lamentables precedentes de una escalada de violencia que se institucionalizaría con el Golpe de Estado de 1973 y la implantación de la dictadura cívico-militar, donde la experiencia organizativa de los trabajadores 
ferroviarios se ve truncada por la violencia hegemonizada por la Junta Militar de Gobierno desde el martes 11 de septiembre de 1973 como fuerza fáctica que irrumpió y destrozó las formas de vinculación comunitaria, las redes sociales y todo lo que significó la organización ciudadana amplia durante los sesentas y que cuajó en definitiva en la articulación de la Unidad Popular. Esto no es menor, porque como ha sido revisado recientemente, la Unidad Popular representó para la comunidad ferroviaria el momento donde se encontraban ad portas de una transformación estructural del país.

Este anhelo arraigado se observa en el relato del herrero y actual dirigente de la Corporación Mutual de Ex Funcionarios de Ferrocarriles del Estado de Valparaíso, Darío Muñoz:

"Nos sentíamos explotados todavía, nosotros éramos explotados. Nosotros queríamos algo mejor para nosotros, para el país, para nuestros hijos. Entonces, aquí en Valparaíso el presidente Allende sacó la primera mayoría... aquí en Valparaíso... y, como le digo, los cerros impregnados de lo que era". DM (AOMBV, 2013a, ext.: 10:05-11:35)

Sin embargo, en un momento todo cambió drásticamente: la vida desarrollada hasta entonces se vio amenazada por una nueva fuerza que paralizó, reordenó y se expandió constituyendo un nuevo sentido común opuesto a la práctica política de su organización. Se trataba, sin duda, de una fuerza antagonista:

"Llegar el día martes 11 aquí a la Maestranza y vimos lo que pasó, y tuvimos que devolvernos para la casa. El día viernes fuimos, el día viernes se nos llamó por radio en un bando militar, porque eran bandos, se nos reglamentaron hasta el modo de andar, se nos reglamentó en la Maestranza. Llegaron bandos, se nos prohibió hasta la palabra 'compañero'. Se nos prohibió andar más de dos en la Maestranza, no podíamos andar de a tres, teníamos que andar de a dos, vigilados por los militares. A nosotros se nos colocó gente del Regimiento Maipo”. DM (AOMBV, 2013a, ext.: 10:05- 11:35) La relación contractual con la Empresa cambió; los trabajadores ya no participaban de su administración y, más grave aún, trabajaban en 
un recinto donde el trabajo fue normado militarmente, perdiendo todo los derechos sociales y políticos además de las prácticas de la vida cotidiana en dicho entorno. Al pasar a ser administrada por los militares, quienes tenían nuevas reglas que implicaban dejar de lado algunas formas de relacionarse a las que estaban acostumbrados, y además comenzaron a vigilar y limitar la conducta de los ferroviarios. Los ahora ex ferroviarios sienten en lo más profundo este cambio:

"Los que vivimos esa época de terror, yo creo que no nos enorgullece para nada esa, esa época negra de la dictadura, porque la vivimos en carne propia. Me recuerdo yo que el día 15 fuimos llamados para integrarnos a la Maestranza, y se nos pasó por un cedazo. Íbamos entrando y en base a una lista que tenía un militar ahí en un escritorio, iban dando los nombres de la gente. Nos pusieron en una fila, íbamos entrando, y ese compañero que estaba con tiqueado como marxista no entraba. La gente de la Unidad Popular no entraba. Fueron muchos los compañeros que fueron exonerados ese mismo día, tomados presos y llevados a los centros de tortura. Fue una época que... aunque uno no la quiera recordar, en algún momento sale a flote, porque esto pasarán generaciones, generación tras generación, y esto no se va a borrar". DM (AOMBV, 2013a, ext.: 00:10-03:57)

En ese marco temporal entonces toma lugar el quiebre de la forma de vida que dio sentido y fuerza a los trabajadores ferroviarios, lo que se entenderá en los trabajadores como la pérdida de la articulación asociativa y solidaria que sucede como causa del terror, la constante humillación y el consecutivo trauma, lo que repercutió sin duda alguna en la disolución de gran parte de tejido social, cultural y político de la comunidad. Como bien o indica Rubén de la Fuente, administrativo, y hasta la fecha dirigente de la Corporación Mutual Ferroviaria de Salud (COMUFERSA):

"Se consolidó todo eso hasta el año 1973, fuerte, fuerza, dinámica, todas esas cosas, pero desgraciadamente vino un movimiento que fue mucho más, más potente, más poderoso, que fue la dictadura. Entonces la dictadura... la dictadura fue lo que asfixió a toda la 
clase trabajadora, no sólo ferroviaria, de todo Chile hasta desde de, de su conducta, entonces esos movimientos fueron dejando, eh... cosas inconclusas" RdlF (AOMBV, 2010, ext.: 10:05-11:35) A lo que Darío Muñoz añade:

"Llegada la dictadura, los trabajadores fuimos inmovilizados totalmente. Nuestras agrupaciones mayores, federaciones, asociaciones de trabajadores y sindicatos de trabajadores fueron totalmente hechos tira, totalmente". DM (AOMBV, 2013a, ext.: 00:01-02:14)

"Tuvimos cuatro días sin trabajar y (carraspea) el golpe nos marcó para siempre, y... nos dimos cuenta de que íbamos a desaparecer, que es lo que hizo. Empezaron a desmantelar la Maestranza, empezaron a echar gente para afuera, y la mayoría si tengo que reconocerlo salimos jubilados pero con sueldos míseros". DM (AOMBV, 2013a, ext.: 00:04-01:11)

La dislocación producida por el golpe de Estado y la entrada de militares a dirigir la Empresa de Ferrocarriles es un trauma recordado como un tiempo de privación de derechos, un tiempo de represión política y maltrato en el que tuvo lugar el desmantelamiento de su espacio laboral. Junto a los despidos y jubilaciones forzadas, los militares modificaron las formas de convivencia que hasta ahora conocían los ferroviarios dentro del trabajo. Así lo recuerda Alejandro Guerrero, maquinista y dirigente de la Sociedad Mutualista Santiago Watt:

"Exacto, bueno, alguno lo echó de la Empresa y a otro no lo echó, lo mató. Entre ellos un compañero nuestro, maquinista, el presidente mártir le decimos, porque era el presidente de la Federación en el período en que, en que se dio el golpe de Estado". AG (AOMBV, 2013b, ext.: 00:07-00:28)

Esta nueva administración no solo significó despidos y jubilaciones forzadas, sino también la muerte de quienes pensaban distinto. Fue el desarme de un proyecto obrero con identidad de clase, que conectaba los principales componentes de su vida; entre ellos, el trabajo, la federación y el sindicato, elementos estratégicos de su vida. De este modo, el relato sobre este pasaje significó 
descomprimir emociones ligadas al dolor y la pérdida, aflorando la nostalgia, la rabia, la impotencia. El volumen de la voz en el relato baja, se ralentiza y el brillo en la mirada se apaga. El rostro del entrevistado

muestra gran emoción al recordar a su compañero asesinado, le tirita la voz y los pómulos se enrojecen. Así continua el relato de Alejandro Guerrero:

"Es el caso que más recuerdo yo, que nos toca muy directamente a nosotros. Fue el presidente de nuestra Federación aquí, y hay otros compañeros de otras partes que también cayeron, en otras secciones, en otra casas de máquinas y en otra regiones, porque en Santiago, creo que en la maestranza también hicieron la, dejaron la escoba ahí. Aquí en Barón también, se llevaron a varios". AG (AOMBV, 2013b, ext.: 00:31)

Esto lo profundiza luego Darío Muñoz, diciendo que había:

"Mucha tensión, muchos de nosotros llegábamos, muchos compañeros después de ser tomados detenidos y torturados dejaron... murieron muchos de ellos a los seis, ocho meses. Yo era testigo del taller mío, era uno de los talleres de, el 90\% éramos de izquierda”. DM (AOMBV, 2013a, ext.; 03:29-05:51)

Con la muerte y desaparición -como se señala en los relatosdel líder de su Federación (Fernando Navarro Allendes) y otros compañeros en regiones (Maestranza San Bernardo por ejemplo), se buscaba silenciar la articulación que tenían con las organizaciones sindicales a lo largo del país, las que hasta ese momento adherían y daban sustento sindical a la Unidad Popular. Dice Darío Muñoz:

"Esto duró aproximadamente seis meses, ocho meses. Una vez que ellos consideraron que estaba todo desarticulado, sacaron a los militares de la Maestranza, y esto fue a través de todo el país. Y no tan solo a la Maestranza, a todos los sindicatos, empresas privadas y todo lo que tenía relación con la Compañía Chilena de Tabaco, la mejor fábrica que hay aquí en Valparaíso, privada, dueños los ingleses de esa fábrica. Mi padre trabajó más de cuarenta años (...) desarticularon todas las industrias, empezaron a llevarse las industrias, aquí existían, aquí estábamos llenos de industrias. Yo 
no sé Valparaíso cómo sobrevive, porque aquí teníamos la Chilena de Tabacos, teníamos la Costa, teníamos la Hucke, teníamos la imprenta, grandes imprentas modernas, teníamos el astillero Asaba; que el astillero Asaba no eran todos militares, trabajaba mucha gente del sector, eh, ¿cómo se llama? eh privado. Luego todos eran contratados en esos años por las Fuerzas Armadas y los ferroviarios, portuarios, portuarios que era un gremio tan grande desarticulado totalmente; los ferroviarios por otro lado. Se llevaron todas las empresas de aquí de Valparaíso". DM (AOMBV, 2013a, ext.: 00:01- 02:14)

En específico sobre el Complejo Ferroviario Barón, Roberto Ramos dice:

"Cuando se empieza a socavar el sistema ferroviario, eh, vivo la experiencia de haber trabajado en una locomotora, ponte tú del turno de las 7 hasta las 15 horas, y nos piden: "Oiga, tráigame esta locomotora, déjemela aquí en la tornamesa". Y estaba un señor ahí con un con un equipo de oxígeno y empiezan a cortarla en chatarra. Una locomotora que había servido en el curso de la mañana, haciéndole la pega en el patio y después de haberla dejado puesta allí, eh, viene un soldador y empieza a cortarla con oxígeno. Y eso creo que marca el inicio de... de esta feroz, digamos, eh, manera de destruir esta empresa". RR (AOMBV, 2013c, ext.: 05:00-09:17)

Al respecto, Alejandro Guerrero da cuenta del boicot del servicio:

"Un automotor salía tipo 06:30 a 07:00, cuando cierto tipo de trabajadores ya había terminado su labor y regresaban a sus casas. Entonces esos trenes se iban abarrotados. Después cuando salían los empleados de las tiendas, todo eso también a otro horario habían trenes que llevaban a toda esa gente, entonces de repente empezaron a adelantarle 15 minutos la salida sin avisarle a nadie, salvo al personal nuestro (...) así que salía el tren obviamente vacío, porque no llegaba nadie; pocos sabían que se había adelantado y tomaban el tren poh. Después cuando llegaba la gran masa no había tren". AG (AOMBV, 2013b, ext.: 00:00-00:56)

Esto se profundiza de la siguiente manera:

"A medida que iba pasando el tiempo más trenes eliminaban, 
medios recorridos había entonces, empezó. Yo no tenía espacio pa' arriba. De hecho, de hecho hay algunos, parte de mis compañeros ahí que llegaron, y jefes, los mismos jefes: "Oigan, cabros, váyanse que esto no tiene futuro, váyanse, están en tiempo de marchar para encontrar otras pegas", y muchos de mis compañeros partieron". RR (AOMBV, 2013c, ext.: 00:07-02:52)

Con la desarticulación de la fuerza obrera en Valparaíso y el desarme de un aún emergente proceso de cordones industriales a lo largo del país, se produce una dislocación de una clase social que fue en el mejor de los casos silenciada. Se estableció una relación negada, un quiebre que generó un cambio irreparable en su forma de comprender y enfrentarse al mundo hasta el momento. El relato es en este punto una forma de sacar a la luz lo vivido, como forma de prevenir y evitar, así como también de lavar heridas y encontrar cierto consuelo. Sin embargo, existe cierta nostalgia de lo que para ellos significó la pérdida de varios proyectos imbricados, como por ejemplo:

- La organización ferroviaria y el esfuerzo por unificar el país a través del ferrocarril.

- La organización sindical de los ferroviarios y sus esfuerzos por mejorar su vida laboral.

- La carrera ferroviaria y su relación con el mejoramiento del bienestar personal y familiar.

- La construcción de identidad colectiva a partir de la ampliación de su forma de vida hacia los barrios y territorios.

- El proyecto político que conectaba la forma de vida de los ferroviarios

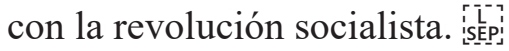

Según la documentación generada por el Archivo Oral, la Empresa de los Ferrocarriles del Estado aún era una empresa pública a mediados de los años setentas, integrada entre sus partes y que respondía a un sistema de coordinación central. Esta situación, como se desprende de los distintos relatos, fue cambiando paulatinamente hasta una descomposición, una separación entre las partes que formaban la Empresa. La irregular privatización de Ferrocarriles y el traspaso a contratistas de muchos de sus tramos 
o secciones, repercutieron en que el proceso laboral ferroviario se hiciera difícil de precisar como un solo conjunto y en que las condiciones de trabajo a que se sometían los operarios y empleados ocupados en distintas secciones o por distintos empleadores, fueran también diferentes.

Para dimensionar lo anteriormente descrito, en el año 1970 trabajaban en la Empresa de los Ferrocarriles del Estado 24.717 personas, en el año 1980 trabajaban 9.800 personas y, en el año 1988, 6.801 personas. Es decir, sólo en 18 años, la masa laboral se redujo a menos de un cuarto al ser despedidos 17.916 trabajadores (Anuarios Estadísticos de la Empresa de Ferrocarriles del Estado de Chile). Tal como lo señala Jaime Ruiz-Tagle, la instalación del régimen tiene amplios efectos en el sindicalismo del país:

"Luego de un golpe de Estado, en 1973 se instaló en Chile un régimen político autoritario, que reprimió duramente al movimiento sindical y especialmente a los dirigentes de izquierda, desarticulando sus organizaciones. Por otra parte, tendió a disminuir y luego a desaparecer el rol del Estado como impulsor directo del desarrollo económico. La responsabilidad del desarrollo se entregó a las llamadas 'fuerzas del mercado', particularmente a las grandes empresas privadas, nacionales y transnacionales (...) Pero esta crisis política no fue la única que afectó al sindicalismo chileno. Con la implantación del régimen militar se produjo también una crisis jurídica: desaparecieron o se desvirtuaron las leyes o normas que habían hecho posible el surgimiento y desarrollo de las organizaciones sindicales. En otro nivel, se produjo una crisis estructural, como consecuencia de la aplicación de un modelo económico neoliberal, que provocó alto desempleo y un fuerte deterioro del sector manufacturero, principal base histórica de las organizaciones sindicales" (Lira y Rojas ed., 2009: 18-19).

Como queda en evidencia tras el análisis de los testimonios de los ex trabajadores del Complejo Ferroviario Barón de Valparaíso, la reducción de personal que afectó al conjunto de la empresa se debió a la política económica del régimen militar, poniendo 
en peligro la sobrevivencia de las empresas públicas al otorgarle un papel preponderante a la actividad económica privada, terminando por reducir el aporte fiscal a Ferrocarriles a partir del año 1979, lo que explica la progresiva restricción de los recursos humanos empleados. Con el fin del subsidio fiscal, la empresa se fue progresivamente transfiriendo a contratistas privados, de esta forma, otros trabajadores hacen lo que antes hacían los ferroviarios. Dicho tránsito fue abruptamente fortaleciendo una política de máxima utilización del recurso humano llevándola al extremo a mediados de los ochentas, lo que explica también los despidos masivos y jubilaciones anticipadas que se acompañan de aumentos en la carga de trabajo para los que quedan.

Los trabajadores ferroviarios tuvieron tradicionalmente remuneraciones que les permitían acceder a un nivel de vida digno, donde el dinero alcanzaba para cubrir las necesidades básicas -quedando documentado, por ejemplo, en los testimonios de Rigoberto Núñez o Mario Tapia-, la gran mayoría de ellos se hizo propietario de su vivienda, sus hijos tenían oportunidades de educación y una perspectiva laboral clara, disponían de tiempo y recursos para recrearse desarrollando actividades deportivas y sociales (los administrativos recuerdan con gusto los "viernes sociales" o los obreros de maestranza la "comida mensual", entre otros); los trabajadores habían logrado un sistema salarial fundado en un sueldo base al que se agregaba un significativo incentivo de producción (grupal o individual) y un conjunto de beneficios, algunos de los cuales conservan.

A medida que aumentaban las necesidades y gastos, propios del crecimiento de cualquier familia, los ferroviarios tenían una oportunidad cierta y objetiva de ascenso a lo largo de la vida laboral: la carrera funcionaria y el escalafón lo hacían posible. La pérdida del poder adquisitivo de los trabajadores del gremio fue gradual y sistemática a lo largo de los últimos años de la Empresa. Ya en el año 1974 -según lo recuerda un dirigente histórico de la Federación Santiago Watt como Miguel Ordenes-, los sueldos del personal de Ferrocarriles fueron encasillados dentro de los 
niveles de renta dados por la Escala Única de Remuneraciones para el Sector Público, lo que significó, igual que para el resto de los trabajadores del país, una caída muy importante en sus ingresos. A los incentivos de producción que representaban hasta un $600 \%$ del sueldo base se les puso un tope de $30 \% \mathrm{y}$, al ponerse fin a la carrera funcionaria en 1979 junto con la aplicación del Plan Laboral de José Piñera, se estancó la situación económica de muchos trabajadores o se establecieron grandes limitaciones a sus ascensos.

Hasta el año 1976, los ferroviarios tenían beneficios en atención a la salud que cubrían el 100\% del valor de las consultas médicas, hospitalizaciones y medicamentos, así como de la atención dental. A partir de ese año debieron pagar el 50\% del valor total de ellas, valor que progresivamente fue aumentando con el tiempo, para que en el año 1981, los ferroviarios entraron al sistema general establecido para todos los trabajadores chilenos, cotizando en la actualidad el 7\% de sus remuneraciones para las prestaciones de salud, significando otra forma de reducción de sus sueldos. Además de lo anterior, hay otras pérdidas más indirectas pero que repercuten también sobre una disminución en la calidad de vida evidenciadas por los trabajadores como, por ejemplo, el fin de la Cooperativa de Ahorro Ferroviario, de las colonias de verano de los hijos de los trabajadores, la reducción de los pasajes liberados para la familia ferroviaria, la obligación de pagar un arriendo por las casas de la empresa de los funcionarios que deben vivir dentro de ellas, la pérdida de la jubilación por antigüedad y el feriado progresivo y, por supuesto, el término del Servicio de Bienestar.

Afortunadamente, desde el año 1980, los trabajadores ferroviarios comienzan a negociar colectivamente sus condiciones de trabajo y remuneraciones, conservando la reajustabilidad de sus sueldos según el 100\% del IPC. Sin embargo, a pesar de ello, la caída que provocó la recesión de los años 74-76 fue de tal magnitud que la situación concreta de los bajos sueldos fue hasta fines de los ochentas uno de los problemas comunes del conjunto de los gremios ferroviarios, disminuyendo notablemente para todos los 
trabajadores del sector y resintiendo a unos estamentos más que otros como, por ejemplo, operarios de vías y obras, cuyos sueldos base promedio en abril de 1988 fluctuaban entre $\$ 20.000$ y $\$ 25.000$ pesos, son de los más afectados entre los obreros. Por su parte, los administrativos -como Rubén de la Fuente u Oscar Carvajal-, que tenían relaciones formales e informales muy gratificantes, deben muchas veces saltarse la colación para poder cumplir con el sistema de pequeños endeudamientos al que tienen amarrados sus sueldos. Esos son algunos casos para graficar sus condiciones.

\section{LA SOLIDARIDAD EN RED}

Sin embargo, es en la decada de los ochentas donde se comienza a dar una rearticulación de la fuerza sindical ferroviaria. El primer hito que puedo identificar es el Comité de Solidaridad creado al Interior de la Federación Santiago Watt, quienes organizaron una estrategia en base a cuotas de su sueldo para acudir en ayuda de quienes eran despedidos. Esta estrategia se narra en el relato de Roberto Ramos:

"Una de las cosas más lindas que yo he vivido como hombre, que cuando se quedaron fuera los muchachos, se forman grupos para ir en ayuda de ellos, y yo me recuerdo que formé parte de esa, de esos grupos que recolectábamos, ehh, mercadería, ponte tú, y se diseñó tan bien hecho todo que cada uno tenía la, por ejemplo, lo dejaba llevar un tarro de jurel, ponte tú, al otro un kilo de azúcar y también se metía la mano al bolsillo, ehh, para poder hacerle la renta más o menos parecida a lo que teníamos todos, te das cuenta, y eso era impresionante porque un muchacho que ganaba -nosotros que ganábamos muy poco dinero, pero colocábamos igual que el otro que ganaba más lucas-, si era ponte tú 100 pesos, 100 pesos era pal que ganaba menos lucas y 100 pesos colocaba el otro, entonces era parejito. Y después se le entregaba a cada uno de ellos como que tenían una una más menos parecido del sueldo y esa etapa duró los dos años. Y después cuando regresan los muchachos y dicen: "Ya, compadre, usted estaba aquí y aquí vuelve", o sea, volvió al mismo lugar de su escalafón. Claro, eh, o 
sea, yo te digo, eso eso es lo más bonito, diría yo, entre todo, entre el dolor, y las cuestiones. Es bonito, es una cosa que recuerda uno con agrado, ah, esa esa manera de ser solidario". RR (AOMBV, 2013c, ext.: 05:19-06:50)

Esta adaptación de la vida ferroviaria en el contexto del golpe de Estado que se evidencia en el relato, en sus relaciones y en el compromiso con quienes formaban parte de su familia ferroviaria, da cuenta de que hacer un sacrificio era parte de su forma de lucha y resistencia, de justicia e identificación con sus compañeros de trabajo y de vida. Así mismo, se generaron grupos que se organizaron para el ahorro y acceso de la vivienda como de artículos de necesidad básica. Esta articulación económica orientada al consumo, buscaban compensar colectivamente aquello de lo que se carecía individualmente, reconstruyendo el compromiso y la solidaridad. Así lo deja ver Gregorio Fernández, maquinista: "La unidad de nosotros nos llevaba hacer cosas juntos. Formamos un grupo... El primer grupo para comprar se nos ocurrió buscar una juguera Sindelita 2000 en ese tiempo. Yo te hablo del año 74 y 75, por ahí, y elegimos ese grupo. Entonces todos compraban. Éramos diez, entonces, todos... todos estábamos comprometidos a pagar la cuota si el otro se la sacaba. Después seguimos con una tele... Costaba un mundo comprarse un televisor Antu de 12 pulgadas. Ese era el valor que teníamos que juntar. GF (AOMBV, 2013d, ext.: 00:00-05:27)

Pero sin lugar a dudas, la emblemática huelga de 1988 es el hito de solidaridad más grande desarrollado, que consistió en un paro de actividades por más de 18 días, donde se demandaba mayores niveles de seguridad laboral además de una impostergable mejora en las condiciones de trabajo, no fué un fenómeno meramente espontáneo, basta observar la declaración efectuada por el presidente de la seccional Primera Zona de la Federación Santiago Watt en el nacimiento del sindicato Santiago Watt Barón, para hacernos una idea de aquello:

"En el ampliado desarrollado en 1975 manifestábamos: Hoy debemos examinar los problemas pendientes, reorganizar y 
revitalizar nuestra Organización, hacernos el ánimo de levantar la moral de los derrotistas. Los momentos que vivimos son difíciles y estamos defendiendo nuestros derechos en condiciones muy inferiores a las que siempre tuvimos, estos son, por lo tanto, los momentos en los que nuestra Federación debe tener su estructura más sólida, porque los hombres y las sociedades se conocen en los momentos difíciles, esta es nuestra tarea que comienza hoy: UNIDAD, DIGNIDAD Y ORGANIZACIÓN [sic] debe ser nuestro lema" (Memorias de la seccional Primera Zona de la Federación Santiago Watt, 1980)

El 12 de abril de 1988 los trabajadores ferroviarios decidieron parar. Fue la decisión mayoritaria tomada por el gremio frente a la Dirección de la Empresa que respondió a sus demandas despidiendo a 101 trabajadores, 17 de los cuales eran dirigentes sindicales. Este hito fue una larga huelga, altamente recordadas por los trabajadores registrados en el proceso de investigación, donde las reivindicaciones del movimiento demandaban la reincorporación de los exonerados de la dictadura, el retiro del Director de la Empresa y la delimitacióndel proceso de privatización que sólo beneficiaba a los contratistas privados.

El paro terminó el 30 de abril del mismo año, sin reintegrarse 72 trabajadores. Y si bien no se lograron los grandes objetivos propuestos, esta acción nucleó al gremio en torno a sus problemas comunes, le permitió identificar con claridad el soporte cotidiano del servicio que hacen su trabajo y alertó en forma ejemplar a la comunidad nacional sobre la pérdida de un patrimonio de todos los chilenos. Dado todo lo anterior, es posible comprender que los trabajadores ferroviarios emprendieron acciones en defensa de sus condiciones de trabajo, que van desde el trabajo diario y la vigilancia de las irregularidades laborales hasta la denuncia pública, las reivindicaciones y el paro. Sin embargo, es también perceptible de sus testimonios un sentimiento de disconformidad, principalmente a nivel gremial, por el sentimiento de que podían haber hecho más.

Más allá de aquello, en las adversas condiciones de trabajo 
descritas a nivel interno de la empresa y a las condiciones político-económicas que se vivieron en el país desde 1973 a 1989, es necesario reconocer que los trabajadores ferroviarios cumplieron un rol protagónico. Este no se circunscribió a la defensa de la fuente laboral desde la denuncia y la organización, sino que desde allí se tradujo en pensar y elaborar propuestas para enfrentar la situación diagnosticada.

En la coyuntura nacional de mediados de los ochentas, que abría progresivamente caminos a la democracia mediante la participación social, estas proposiciones cobraron mayor validez y factibilidad. Algunas de sus principales propuestas, canalizadas a través del "Manifiesto Ferroviario" de 1988 y el IV Congreso de Organizaciones Sindicales Ferroviarias de 1989, entre otras, relacionadas con las condiciones de trabajo, higiene y seguridad, planteaban a la Empresa: "Detener y revisar el proceso de privatización de Ferrocarriles. (sic)

Elaborar un plan de recuperación (sic) de equipo inutilizado.

Elaborar un programa planificado -estableciendo órdenes de prioridades de modernización y cambio tecnológico. (sic)

Hacer un programa que garantice condiciones sanitarias mínimas. (sic)

Establecer un sistema de organismos de control internos y externos. (sic)

Reestablecer la carrera funcionaria. (sic)

Establecer una política de personal (sic) que garantice el trabajo de personal calificado.

Clarificar la situación legal de Ferrocarriles frente al seguro contra accidentes y enfermedades profesionales (sic).

Fortalecer un Departamento de Seguridad Industrial y Capacitación (sic). (Manifiesto Ferroviario, 1988).

De la misma forma, planteaban responsablemente a los propios trabajadores y sus organizaciones sindicales:

"Elaborar un plan de capacitación permanente (sic) en higiene y seguridad.

Incorporar en la Negociación Colectiva (sic) reivindicaciones sobre 
condiciones de trabajo y salud laboral.

Hacer uso de la legislación (sic) vigente (Comités Paritarios de Higiene y Seguridad, ley 16.744, también en materias de prevención de riesgos laborales y derechos a prestaciones médicas y económicas) Introducir (sic) el problema de las condiciones de trabajo y salud laboral en las organizaciones sindicales (sic)".

(Manifiesto Ferroviario, 1988).

En el mes de septiembre de 1989, las organizaciones sindicales ferroviarias entregaron a los partidos políticos de la "Concertación por la Democracia" un extenso documento con la finalidad de "presentar un diagnóstico y proponer un plan de acción" tendiente a devolver a esta institución, patrimonio de todos los chilenos, "su condición de herramienta de progreso y su carácter de apoyo al transporte de las riquezas del país”. Allí señalan además que "los trabajadores serán los principales actores para el logro de estos objetivos". Por supuesto que, su propuesta no fue considerada.

Sin embargo, al ver la coyuntura nacional de lo que pasaba en Chile el año 2011 (y aún hoy en día), un dirigente como Roberto Ramos dice:

"Lo que miro hoy día y ojalá resulte a estas nuevas generaciones de los estudiantes que lograron de alguna manera eh... esto, esto que vivimos anteriormente nosotros, de volver a buscar a su par, de volver a creer en el de al lado, de tener la confianza de ir a... a cómo te digo yo, a... a pelear por sus derechos, por sus cosas que le corresponden". RR (AOMBV, 2013c, ext.: 09:57-10:46)

Al observar la acción colectiva de las nuevas generaciones les da fuerza para contar su versión. Es una forma de evitar el olvido, de mantener la forma de vida andando, aunque sea en la memoria y con ello encontrar sentido en lo que queda de ella. Reciprocidad intergeneracional y solidaridad. Hay un deseo por darle algo a sus hijos, una herencia tal como lo hicieran con ellos amigos, padres y/o abuelos, como una manera de mantener la esperanza de la vida y con ello el futuro abierto. Esto se aprecia en el relato de Roberto Ramos:

"Si pudieran, si pudiera esto tener un resultado, eh, yo sería eh 
muy feliz, hueón, de que esto pudiese ayudar a los más jóvenes. Creo que eso, esa es la tarea. Cómo, cómo, a ver, cómo los muchachos más jóvenes con esta, con esto que hacen ustedes de poder transmitir... claro la cuestión visual, la cuestión digamos eh... oral donde se están transmitiendo eh... experiencias vividas, eh... es como poder, eh decirle: "Mira así nos podemos organizar, organízate en tu barrio, anda a la junta de vecinos, anda a tu club deportivo vuelve, vuelve a ese tema que es lo que realmente lo que hace que uno tenga estos valores o tenga esto..." Esto digamos, estos estos compromisos contigo mismo, con la sociedad, con el de al lado y no y salirte, salte de esa cuestión que es ser tú, no soy tú solo, hay más gente al lado tuyo". RR (AOMBV, 2013c, ext.: 06:56-08:11)

Si bien hoy ya no está presente el contrato asociativo de antes, sin embargo, en la unidad de las luchas multisectoriales del presente, se encuentran gérmenes de experiencias organizativas como las narradas hasta aquí que bien podrían articular un presente más digno y fraterno para todas y todos.

\section{Conclusiones}

Durante el siglo XX el concepto de patrimonio se ha expandido y profundizado relevando especialmente lo monumental, pero en las últimas décadas su comprensión es cada vez más diversa al incorporar bienes, ideas, procesos y formas de vida que, hasta hace no mucho tiempo, simplemente no se consideraban o estaban desprovistas de cualquier tipo de valoración. Sin embargo, cada vez con más fuerza, distintas comunidades y grupos de interés, han sido capaces de oponerse a visiones parciales del pasado y a develar los silencios y olvidos de la historia oficial, también como resultado de la crisis de legitimidad y representación que han devenido sobre las organizaciones públicas y privadas tanto en Chile como en el mundo.

Desde un punto de vista político, es interesante destacar la forma en cómo se ha abordado en Chile el patrimonio industrial y, en particular, el patrimonio ferroviario, todavía con un foco que 
privilegia las arquitecturas y tecnologías por sobre los procesos socioculturales de los hombres y mujeres que trabajaban allí. En ese sentido, en la historia oficial chilena y, particularmente, la de una ciudad-puerto como Valparaíso, destaca la relevancia estratégica de los ferrocarriles en la construcción y unificación del territorio. En tal sentido, y continuando con el análisis desde la perspectiva patrimonial, si bien el Estado ha declarado como monumentos históricos nacionales muchos bienes del sistema ferroviario, sean estaciones, puentes, locomotoras, carros e incluso líneas ferroviarias, al mismo tiempo y contradictoriamente, ha llevado a la práctica políticas directas e indirectas de destrucción de dichos bienes, incluso los que estaban protegidos por la legislación de monumentos nacionales, como en el caso del Complejo Ferroviario Barón de Valparaíso.

En esta contradicción, lo más grave es la invisibilidad, el silencio y la desvaloración del patrimonio que reside en quienes hicieron posible su construcción y operación por más de siglo y medio. Como bien diría Renan, el olvido o el error histórico son factores esenciales en la creación de una nación y de aquí que el progreso de los estudios sociales y culturales sean más bien un peligro para ese relato de unidad construido sobre la violencia de unos sobre otros. O como bien nos lo recuerda persistentemente Benjamín, la historia es lo que vela lo que ha sido, la memoria de los vencidos.

El ethos ferroviario de Valparaíso tiene esa caracterización: la de una experiencia invisibilizada por el relato "grande y único" de Chile. Una memoria subalterna, una tradición que la historia oficial no había sentido necesidad de considerar porque el grupo nacional se había construido a menudo sobre su sofocación, sobre su silencio. Específicamente, la memoria narrada por los trabajadores de la Empresa de Ferrocarriles del Estado, del sector norte de la ciudad de Valparaíso, da cuenta de un acontecer situado profundamente afectado por la dictadura militar, a raíz de su valor estratégico referido a su inclusión activa en los procesos democráticos populares y su correspondiente adhesión a la tarea 
impuesta por la Unidad Popular de fortalecer y socializar los medios de producción. Es decir, este debilitamiento al punto de la invisibilidad, como lógica naturalizante, fragmenta una vía de comunicación nacional que es asimilable a una arteria central que bloquea la normal transmisión sanguínea de cualquier cuerpo, irrumpiendo en su plenitud global al punto de la desaparición y olvidar. Este macro-proceso tuvo sus correlatos en las historias de vida de cientos de trabajadores extraídos y despojados de ese patrimonio.

Como ha quedado demostrado en la investigación, los ferrocarriles superaron su valoración exclusiva como medio de transporte, complejizando esta lectura desde las experiencias políticas, económicas y organizativas que circularon en torno a la empresa, sus trabajadores, familias y círculos vinculantes. Los trabajadores ferroviarios, que a fines del siglo XIX e inicios del XX constituyeron sus primeras organizaciones inspiradas en el movimiento mutualista como la Sociedad Santiago Watt, y el movimiento sindical, como la Federación Obrera de Chile, no sólo priorizaron el apoyo mutuo o la reivindicación gremial sino que también tuvieron conciencia acerca del necesario progreso en materia de derechos económicos, sociales y culturales, cuyas prácticas y experiencias subsisten hasta el presente y que se siguen vinculando, problemáticamente, con el presente de nuestra sociedad en materia de trabajo, educación, salud y previsión. Existe allí un modelo de trabajo, una experiencia organizativa, que resulta útil, en su condición ética y estética, para las nuevas experiencias organizativas y políticas que se sitúan en otro paradigma -por descubrir plenamente- del que ha constituido la práctica política institucional, hoy en crisis de sentido y forma.

Por esta razón, la propuesta de Archivo Oral apunta a ampliar $\mathrm{y}$ fortalecer las instancias de la comunidad ferroviaria viva para defender el patrimonio que nos concierne a todos, haciendo un uso concreto de estas memorias como nuestro patrimonio en el fortalecimiento y la formación de los movimientos sociales y políticos del presente y las urgencias que están por venir. 


\section{REFERENCIAS}

DoCUMENTOS HISTÓRICOS

Anuarios Estadísticos de la Empresa de Ferrocarriles del Estado de Chile.

Revista FEFCH (1972). Santiago de Chile: Imprenta FF.CC. del Estado.

Federación Santiago Watt (1980). Memorias de la seccional Primera Zona de la Federación Santiago Watt. Valparaíso: Autoeditado. Federación Santiago Watt (1988). Manifiesto Ferroviario. Valparaíso: Autoeditado.

\section{DOCUMENTOS ORALES}

Gregorio Fernández [AOMBV, 2013, material de estudio, HD video, almacenado en disco óptico]

Rubén de la Fuente [AOMBV, 2010, material de estudio, MINI $\mathrm{DV}$, almacenado en disco óptico]

Alejandro Guerrero [AOMBV, 2013, material de estudio, HD video, almacenado en disco óptico]

Darío Muñoz [AOMBV, 2013, material de estudio, HD video, almacenado en disco óptico]

Roberto Ramos [AOMBV, 2013, material de estudio, HD video, almacenado en disco óptico]

LIBROS

Lira, E. y Rojas, H. (2009). Libertad sindical y derechos humanos. Análisis de lis informes del Comité de Libertad Sindical de la OIT (1973-1990). Santiago de Chile: LOM Ediciones. 


\section{Notas de Página}

1 "Archivo Oral de la Maestranza Barón de Valparaíso", proyecto de ONG Pensar Sur co-investigado junto a la Mg. Carolina Paredes y desarrollado en conjunto con la Asociación de Jubilados Ferroviarios y Montepiadas de Valparaíso, la Corporación Mutual de Ex Funcionarios de Ferrocarriles del Estado de Valparaíso, la Corporación Mutual Ferroviaria de Salud, la Corporación Mutual Ferroviaria Santiago Watt Muirhead, la Sociedad Mutualista Santiago Watt, la Sociedad de Profesionales y Jefes de Servicio en Retiro de Ferrocarriles del Estado de Valparaíso (QEPD), la Sociedad de Socorros Mutuos de Ferrocarriles del Estado de Valparaíso y a la Unión de Obreros Ferroviarios de Valparaíso.

${ }^{2}$ Junto a la Corporación Mutual Ferroviaria Santiago Watt Muirhead hemos instalado un memorial en la Estación Puerto de Valparaíso como acto de reparación a los trabajadores hasta ahora reconocidos: Fernando Navarro Allendes, maquinista dirigente de la Federación Santiago Watt, de la CUT Provincial y militante comunista, quién fuera detenido el 13 de diciembre de 1976 en Santiago por organismos de seguridad, permaneciendo en calidad de detenido desaparecido hasta la actualidad. También a Pedro Oyarzún Zamorano, mecánico y militante comunista, quién fuera detenido el 28 de septiembre de 1973 y ejecutado el 6 de octubre del mismo año en el Cerro Chena en Santiago.

Fecha de Recepción del Artículo: 13 Julio de 2018

FECHA DE ACEPTACIÓN: 20 OCTUBRE DE 2019

VERSIÓN FINAL: 25 OCTUBRE DE 2019 